\title{
THE EXPERIMENTAL STUDY OF STRESS-RELATED PATHOLOGICAL CHANGES IN CEREBRAL VENOUS BLOOD FLOW IN NEWBORN RATS ASSESSED BY DOCT
}

\author{
OXANA V. SEMYACHKINA-GLUSHKOVSKAYA*, ${ }^{*}$, VLADISLAV V. LYCHAGOV*, \\ OLGA A. BIBIKOVA*, IGOR A. SEMYACHKIN-GLUSHKOVSKIY*, SERGEY \\ S. SINDEEV*, EKATERINA M. ZINCHENKO*, MOHHANAD M. KASSIM ${ }^{*}$, , \\ AL-FATLE FATEMA ALI ${ }^{*, \dagger}$, AL HASSANI LEITH*, ${ }^{*}$, \\ MARIA V. ULANOVA* and VALERY V. TUCHIN ${ }^{*}, \AA$, \\ *Department of Biology, Saratov State University, Astrachanskaya Str. 83 \\ 410012 Saratov, Russian Federation \\ ${ }^{\dagger}$ Department of Biology, Al-Mustansiriya University, Baghdad, Iraq \\ ¥Institute of Precise Mechanics and Control of Russia Academy of Science \\ Rabochaya 28, 410028 Saratov, Russian Federation \\ ${ }^{\S}$ Optoelectronics and Measurement Techniques Laboratory \\ University of Oulu, P.O. BOX 450090014 \\ University of Oulu, Finland \\ Iglushkovskaya@mail.ru
}

Received 22 May 2013

Accepted 16 June 2013

Published 25 July 2013

\begin{abstract}
In experiments on newborn rats with stress-related intracranial hemorrhage (ICH) using Doppler optical coherence tomography (DOCT) we have shown that latent stage of ICH ( $4 \mathrm{~h}$ after stress) is characterized by decrease of venous blood outflow and the loss of sensitivity of sagittal vein to vasoconstrictor effect of adrenaline. The incidence of ICH (24 h after stress) was accompanied by progression of early pathological changes in cerebral venous blood flow (CVBF) and development of venous insufficiency. Taking into consideration of this fact, we suggest that the suppression of CVBF related to the severity to the deleterious effect of stress on the brain hemodynamics in newborn rats. These facts allow us to conclude that the venous insufficiency with the loss of vasoconstrictor response to adrenaline is an informative and sensitive component of pattern of CVBF that can be important diagnostic criteria of risk of ICH development in newborns.
\end{abstract}

Keywords: Doppler optical coherence tomography; stress-related intracranial hemorrhage; cerebral venous blood flow; adrenaline.

This is an Open Access article published by World Scientific Publishing Company. It is distributed under the terms of the Creative Commons Attribution 3.0 (CC-BY) License. Further distribution of this work is permitted, provided the original work is properly cited. 


\section{Introduction}

Intracranial hemorrhage ( $\mathrm{ICH})$ is defined as the pathologic accumulation of blood within the cranial vault. $\mathrm{ICH}$ is the most common type of brain bleeding in preterm newborns (i.e., low birth weight infants weighing less than $1500 \mathrm{~g}) .{ }^{1}$ In recent years, it was believed that in term newborns ICH is relatively uncommon but largest findings suggest that ICH in term newborns is much more frequent that previously thought. ${ }^{2,3}$ The problem is that unlike preterm $\mathrm{ICH}, \mathrm{ICH}$ in term newborns has different location, multiple etiology, clinical presentation and neurological outcome. ${ }^{4,5}$ The incidence or prevalence of ICH is not known. Only some term infants with ICH present with clinical events, so the true incidence of ICH is difficult to determine. ${ }^{6}$ The lack of diagnostic markers and effective technology for early determination of ICH risk in newborns explains the high rate of neonatal death and less optimistic neurologic prognosis in infants after ICH. ${ }^{7-11}$

The main reasons for ICH in newborns remain unknown. In our previous experimental study, we have shown that stress is a key provoke factor for ICH in adult rats. ${ }^{12,13}$ Others also demonstrate that stress plays a crucial role in development of ICH. ${ }^{14-16}$ Looney et al. hypothesized that in newborns the prenatal stress contributes brain injury and ICH. ${ }^{3}$ The mechanism responsible for stress-induced $\mathrm{ICH}$ are not well understood, but there is strong evidence that stress-related alterations in cerebral blood flow (CBF) may contribute to the pathogenesis of $\mathrm{ICH} .{ }^{17,18}$ Our previous results on adult rats with model of stress-induced ICH indicate that cerebral veins are more sensitive and less resistant to deleterious effect of stress than cerebral arteries. ${ }^{12}$ Some authors demonstrate that impaired venous hemodynamics is implicated in contributing to the occurrence of ICH in newborns. ${ }^{19,20}$ A number of investigators have shown that ICH in newborns is primary venous. ${ }^{21}$ These facts suggest that pathological changes in cerebral venous blood flow (CVBF) can be important marker and sensitive diagnostic criteria for risk of ICH development in newborns. However, there is limited information regarding the particularities of alterations of $\mathrm{CVBF}$ in infants at normal condition and especially during $\mathrm{ICH}$ and the parameters of pattern of CVBF that are informative for the prognosis of ICH in newborns.

Sympathetic nervous system plays a key role in regulation of cerebral circulation from early stage of development organism. ${ }^{22-24}$ Sympathetic vasoconstriction of cerebral vessels has been proposed to be a protective mechanism for the brain, limiting cerebral perfusion and microcirculatory pressure after ICH. ${ }^{25-29}$ Despite intensive investigations in this field, the exact functional role of the sympathetic nervous system in the regulation of the cerebral hemodynamics remains an issue of debate. ${ }^{30}$ Notice, there is limited information regarding the age particularities of adrenergic control of cerebral circulation. ${ }^{26,30}$

There are a lot of techniques providing CBF imaging. The most accepted are positron emission tomography (PET), ${ }^{31,32}$ magnetic resonance imaging (MRI) (including functional MRI), ${ }^{33-36}$ Doppler ultrasound and near-infrared spectroscopy (NIRS). ${ }^{37,38}$ MRI provides high-resolution structural images but needs much time for data acquisition and processing and does not supply with information about blood flow parameters. fMRI and PET use radioactive contrast agents to retrieve the data concerning with blood flow and blood volume in the sample and have relatively low spatial and temporal resolution. Doppler ultrasound and NIRS suffer from ambiguity in decommutation of blood flow velocity and blood flow volume since the raw data usually links to indirect parameters of blood oxygenation level or blood flow level in which both these values enter equally. Besides, Doppler ultrasound and NIRS both cannot provide high spatial resolution functional images. In last years, photoacoustic ${ }^{39}$ and fluorescenc ${ }^{40}$ imaging techniques show potential to visualize microvascular blood flow. However, the tradeoff between penetration depth and resolution is still there. Though multiphoton imaging provides subcellular resolution, scanning area is still limited to hundreds of micrometers, and vice versa the using of acoustic waves improves penetration depths and impairs the resolution. Detailed discussion of advances and limits of imaging techniques listed above can be found in many works. ${ }^{41-44}$ The main idea of these reviews is that in contrast to conventional radionuclide tomography and infrared spectroscopy coherent optical imaging techniques can offer unique combination of characteristics like very high spatial and temporal resolution of functional images, lack of ionizing radiation, variety of contrast techniques, mobility (in order to achieve bedside facility), and finally measuring the blood flow parameters in real units of velocity and geometry of vessels network. Doppler optical coherence tomography (DOCT) is 
one of such techniques. Using DOCT one can measure blood flow in vessels and reconstruct vessels map on the base of OCT speckle image analysis. ${ }^{45-48}$

The objective of this study was to determine the prognostic criteria for pathological changes in pattern of CVBF using DOCT in newborn rats with model of stress-induced ICH.

\section{Methods and Materials}

Subject. Experiments were carried out in mongrel newborn rats weighing 5-6 g. All procedures were performed in accordance with the Guide for the Care and Use of Laboratory Animals published by the US National Institutes of Health. ${ }^{35}$ The rats were housed at $25 \pm 2{ }^{\circ} \mathrm{C}, 55 \%$ humidity, and 12:12 h light-dark cycle. To induce ICH, newborn rats underwent severe stress - effect of intermittent infrasound $(10 \mathrm{~Hz}, 120 \mathrm{~dB})$ during $2 \mathrm{~h}$. The details of performance of experiment modeling of $\mathrm{ICH}$ is described here. ${ }^{49}$

CVBF measuring. The anesthetized rats (thiopental anesthesia, $40 \mathrm{mg} / 1000 \mathrm{~g}$ ) with fixed head and scalp incision were immobilized. The measurement of CVBF performed through the fontanel with focus on the superior sagittal vein (the main trunk) (see Fig. 1). The monitoring of CVBF carried out in rats: (1) in normal condition $(n=12)$; $(2)$ in the masked period of ICH ( $4 \mathrm{~h}$ after stress, $n=20$ ); (3) during ICH (24h after stress, $n=20$ ). To study the capacity of vascular stress-reactivity, we analyzed the sensitivity of sagittal vein to adrenaline $(0.1 \mathrm{mg} / \mathrm{kg}$, Sigma, (iv) in healthy newborn rats $(n=10)$ and stressed rats $4 \mathrm{~h}$ (without ICH, $n=14$ ) and $24 \mathrm{~h}$ (incidence of ICH, $n=14$ ) after stress.

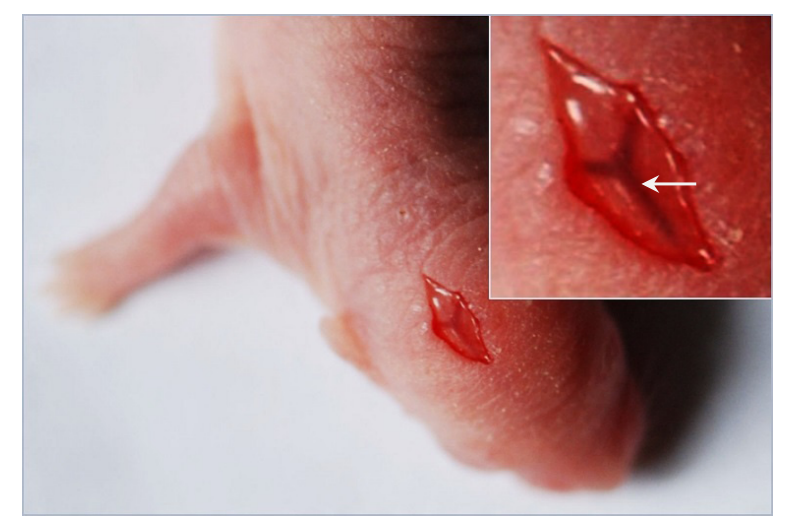

Fig. 1. The imaging of superior sagittal vein in newborn rats through fontanel. The arrow shows the main trunk cerebral vein.
We used a commercially available swept source DOCT system (OCS1300SS; Thorlabs, Inc, USA) with operating at $1325 \mathrm{~nm}$ central wavelength and $100 \mathrm{~nm}$ bandwidth. Longitudinal resolution (in air) was about $12 \mu \mathrm{m}$. Software package supplied with this system allows one to recover Doppler phase map out of the complex form of interference signal resulting from the Fourier transform. The Doppler phase map depicts spatial distribution of moving particles and their velocity. In this map, location of nonzero phase values corresponds to location of vessels in the sample, while magnitude of these phase values relates to blood velocity in the vessels. Because of interferometric data processing, the system implements phase-resolved technique for Doppler frequency shift measurements and phase values are wrapped modulo $\pi$. Such wrapped phase map is produced by the out-of-the-box system software. To solve this problem, we have developed custom homemade software using LabVIEW Development System (National Instruments Corporation, USA) for further processing of original phase maps. The processing algorithm consists of the following steps:

(a) unwrapping phase distribution;

(b) translation of the phase values into the frequency shift according to the system specification (axial scan rate) and

(c) translation of the frequency shift into the velocity according to experimental arrangement's specification (central wavelength of swept source, incident angle and sample refractive index).

Velocity of moving cells was calculated using equation:

$$
V=\frac{\lambda_{0} f_{D}}{2 n \cos \theta},
$$

where $\lambda_{0}$ is the central wavelength of radiation (in vacuum), $f_{D}$ is the Doppler frequency shift, $n$ is the refractive index, been assumed to be equal to 1.4 and $\theta$ is the angle between directions of incident radiation and of cells moving. Equation (1) shows that for particles moving at equal velocities, the major contribution to the Doppler signal give the particles that move at lesser angle against the incident wave. At the same time, incident wave scattered by particles moving perpendicularly to the direction of incidence does not undertake Doppler shift at all. According to the above we assume that waves propagating close to aperture angle of illuminating lens 
generate a major part of the Doppler signal (if the particles move perpendicularly to the optical axis of that lens). Since vasculature in the tissue is of the plexiform this assumption is quite rough, but it allows us to make a simplified preliminary analysis of expected results. Aperture angle of output lens LSM03 mounted in the used OCT system is of $7.5^{\circ}$ according to specs. That value was used in estimation.

The Doppler frequency shift $f_{D}$ is calculated as the OCT signal phase change rate:

$$
f_{D}=\frac{\Delta \varphi}{2 \pi} f_{A} .
$$

Here $\Delta \varphi$ is the phase difference that can be retrieved from the phase maps produced by the Thorlabs software, $f_{A}$ is the axial scan rate which is equal to $16 \mathrm{kHz}$. Since $\Delta \varphi$ is wrapped modulo $\pi, f_{D}$ and $V$ are also wrapped terms. Actual values of $f_{D}$ and $V$ can be recovered using unwrapping procedure.

Statistical analysis. Results were presented as mean \pm standard error of the mean (SEM). The differences from the initial level in the same group were evaluated by Wilcoxon test. Inter-group differences were evaluated using Mann-Whitney test and ANOVA-2 (post hoc analysis with Duncan's rank test). Significance levels were set at $p<0.05$ for all analyses.

\section{Results}

In the first step of our work, we analyzed the changes in parameters of $\mathrm{CVBF}$ in newborn rats in the different stages of development of stress-induced $\mathrm{ICH}$.

The first $2 \mathrm{~h}$ after stress were not accompanied by any changes in CVBF, CVBV was tendentionally decreased $3 \mathrm{~h}$ after beginning of experiment but these changes were not statistically significant. About $4 \mathrm{~h}$ after stress-off was characterized, there were significant changes in CVBF in all newborn rats despite the fact that they did not demonstrate ICH in this poststress period. The diameter of main trunk sagittal vein was essentially increased in stressed rats than in unstressed animals (see Fig. 2). So, after stress the lumen of vein was in 2.1-fold higher compared with one before stress $(0.48 \pm 0.02 \mathrm{~mm}$ vs $0.22 \pm 0.03 \mathrm{~mm}$, $p<0.05)$. The dilation of superior sagittal vein was accompanied by decrease in speed of blood flow $(3.11 \pm 0.42 \mathrm{~mm} / \mathrm{s}$ vs $6.00 \pm 0.09 \mathrm{~mm} / \mathrm{s}, p<0.05)$ reflecting the fall of cerebral venous blood outflow. We did not find progression of above-indicated pathological changes in CVBF during the next $12 \mathrm{~h}$ after stress (see Table 1 ). Thus, $4 \mathrm{~h}$ after stress is the important early period for clear visualization of critical alteration in CVBF in newborn rats.

The ICH was accompanied by progression of above-indicated pathological changes in parameters

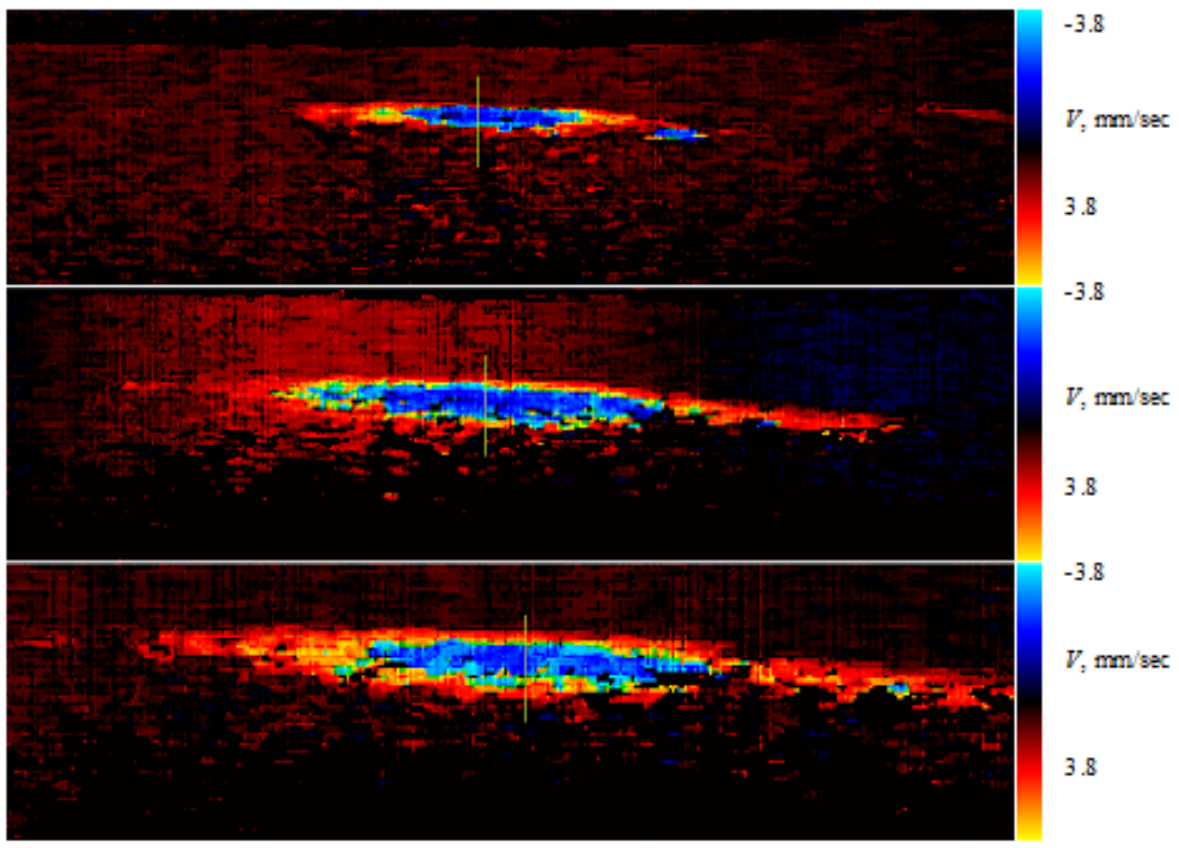

Fig. 2. The velocity map of main trunk sagittal vein in newborn rat under normal condition (a), $4 \mathrm{~h}$ after stress (b) and $24 \mathrm{~h}$ after stress (c). 
Table 1. The changes in diameter of main trunk sagittal vein and velocity of blood flow under normal condition, during $12 \mathrm{~h}$ after stress on newborn rats.

\begin{tabular}{lccccccc}
\hline & $\begin{array}{c}\text { Normal } \\
\text { condition }\end{array}$ & $\begin{array}{c}1 \mathrm{~h} \text { after } \\
\text { stress }\end{array}$ & $\begin{array}{c}2 \mathrm{~h} \text { after } \\
\text { stress }\end{array}$ & $\begin{array}{c}3 \mathrm{~h} \text { after } \\
\text { stress }\end{array}$ & $\begin{array}{c}4 \mathrm{~h} \text { after } \\
\text { stress }\end{array}$ & $\begin{array}{c}8 \mathrm{~h} \text { after } \\
\text { stress }\end{array}$ & $\begin{array}{c}16 \mathrm{~h} \text { after } \\
\text { stress }\end{array}$ \\
\hline Diameter, mm & $0.22 \pm 0.03$ & $0.20 \pm 0.01$ & $0.23 \pm 0.02$ & $0.30 \pm 0.04$ & $0.48 \pm 0.02^{\mathrm{a}}$ & $0.44 \pm 0.05^{\mathrm{a}}$ & $0.50 \pm 0.09^{\mathrm{a}}$ \\
Blood flow velocity, mm/s & $6.00 \pm 0.09$ & $5.84 \pm 0.06$ & $5.91 \pm 0.07$ & $4.88 \pm 0.05$ & $3.11 \pm 0.42^{\mathrm{a}}$ & $3.37 \pm 0.19^{\mathrm{a}}$ & $3.00 \pm 0.22^{\mathrm{a}}$ \\
\hline
\end{tabular}

${ }^{\mathrm{a}} p<0.05$ vs basal levels.

of CVBF (see Fig. 2). So, in newborn rats with ICH the diameter of main trunk sagittal vein was greater in 3.0-fold compared with unstressed animals $(0.67 \pm 0.07 \mathrm{~mm}$ vs $0.22 \pm 0.03 \mathrm{~mm}, p<0.05)$ and in 1.4-fold vs stressed rats without ICH $(0.67 \pm$ $0.07 \mathrm{~mm}$ vs $0.48 \pm 0.02 \mathrm{~mm}, p<0.05)$. The fall of speed of blood flow in dilated cerebral vein was more pronounced in rats with ICH than in stressed rats without ICH and especially compared with healthy rats (see Table 1 ).

In the second step of our work, we investigated the sensitivity of sagittal vein to adrenaline in healthy and stressed newborn rats on different stages of ICH development (see Table 2). In healthy rats, adrenaline infusion was accompanied by constriction of sagittal vein (see Fig. 3). So, adrenaline induced the decrease in diameter of main trunk sagittal vein $(0.10 \pm 0.04 \mathrm{~mm}$ vs $0.20 \pm 0.02 \mathrm{~mm}, p<0.05)$.

Table 2. The changes in diameter of main trunk sagittal vein and velocity of blood flow before and after adrenaline injection in newborn rats under normal condition, $4 \mathrm{~h}$ and $24 \mathrm{~h}$ after stress.

\begin{tabular}{lccc}
\hline & $\begin{array}{c}\text { Normal } \\
\text { condition }\end{array}$ & $\begin{array}{c}4 \mathrm{~h} \text { after } \\
\text { stress }\end{array}$ & $\begin{array}{c}24 \mathrm{~h} \text { after } \\
\text { stress }\end{array}$ \\
\hline \multicolumn{4}{c}{ Before adrenaline injection } \\
Diameter, mm & $0.20 \pm 0.02$ & $0.42 \pm 0.05$ & $0.59 \pm 0.04^{\mathrm{b}}$ \\
$\begin{array}{c}\text { Blood flow velocity, } \\
\mathrm{mm} / \mathrm{s}\end{array}$ & $5.82 \pm 0.06$ & $3.27 \pm 0.02$ & $2.48 \pm 0.07^{\mathrm{b}}$ \\
& After adrenaline injection \\
$\begin{array}{l}\text { Diameter, mm } \\
\text { Blood flow velocity, } \\
\mathrm{mm} / \mathrm{s}\end{array}$ & $0.10 \pm 0.04^{\mathrm{a}}$ & $0.47 \pm 0.03$ & $0.63 \pm 0.04^{\mathrm{b}}$ \\
\hline
\end{tabular}

$p<0.05$ vs: ${ }^{\mathrm{a}}$ basal levels; ${ }^{\mathrm{b}}$ between stressed rats.
The speed of blood flow had tendency to be increased after adrenaline treatment but these changes in CVBF were not statistically significant (6.01士 $0.09 \mathrm{~mm} / \mathrm{s}$ vs $5.82 \pm 0.06 \mathrm{~mm} / \mathrm{s}$ ).

Surprisingly, the stressed newborn rats did not demonstrate reactivity to adrenaline that we observed already on the masked period of ICH. Indeed, adrenaline injection to the stressed rats without ICH ( $4 \mathrm{~h}$ after stress) was not accompanied by any changes in diameter of main trunk of sagittal vein and speed of blood flow $(0.47 \pm 0.03 \mathrm{~mm}$ vs $0.42 \pm 0.05 \mathrm{~mm}$ and $3.42 \pm 0.04 \mathrm{~mm} / \mathrm{s}$ vs $3.27 \pm$ $0.02 \mathrm{~mm} / \mathrm{s}$, respectively). The treatment of newborn rats with $\mathrm{ICH}$ by adrenaline did not cause any changes in parameters of CVBF $(0.63 \pm 0.04 \mathrm{~mm}$ vs $0.59 \pm 0.04 \mathrm{~mm}$ - diameter, $2.59 \pm 0.08 \mathrm{~mm} / \mathrm{s}$ vs $2.48 \pm 0.07 \mathrm{~mm} / \mathrm{s}$ - speed of blood flow).

\section{Discussion}

Collectively, in this study using DOCT we examined the parameters of CVBF and analyzed the vascular stress-reactivity of sagittal vein (adrenaline test) on different stages of development of stressinduced $\mathrm{ICH}$ in newborn rats. Our results show that the deleterious effect of stress on the cerebral venous hemodynamics in newborn rats developed during $24 \mathrm{~h}$, during the first $4 \mathrm{~h}$ after stress (masked period of $\mathrm{ICH}$ ) newborn rats did not demonstrate $\mathrm{ICH}$ but the CVBF was significantly changed. In this period, we observed increase in diameter of sagittal vein with the fall of blood flow velocity. Thus, latent stage of ICH was accompanied by dilation of superior sagittal vein reflecting decreased venous blood outflow. In the next day after stress ICH

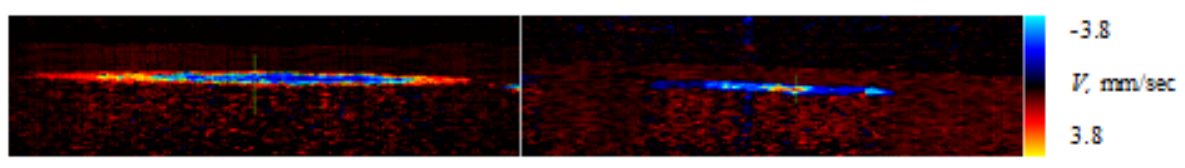

Fig. 3. The velocity map of left branch of sagittal vein before (a) and after (b) adrenaline infusion in newborn rat. 
developed in all stressed rats. Notice that incidence of ICH was characterized by progression of pathological changes in CVBF. The relaxation of sagittal vein and decrease in blood flow velocity were more pronounced in rats with ICH than in stressed rats without ICH (masked period) and especially compared with healthy rats. These facts allowed us to conclude that stress induced gradual suppression of cerebral venous blood outflow and development of venous insufficiency. Others also demonstrate that decrease in cerebral venous blood outflow is implicated in contributing to the occurrence of ICH in newborns. ${ }^{19,20}$ Some studies show that impairment of CVBF with low cerebral perfusion pressure are associated with ICH and poor outcomes after brain injury in children. ${ }^{26,50-52}$ The current 2003 Pediatric Guidelines recommend preventing or rapidly treating venous insufficiency and cerebral hypotension in children. ${ }^{53}$ The clinical data suggest that the ICH in newborns is primary venous. ${ }^{20}$ Thus, suppressed CVBF is closely correlated with ICH in newborns.

The one commonly employed strategy to increase CVBF and cerebral perfusion pressure is to use vasopressors (adrenaline, norepinephrine, dopamine or epinephrine)..$^{54,55}$ Yet, there are no studies describing vasopressor use or comparing vasopressor effectiveness in the setting of pediatric ICH and brain injury. To study the effect of sympathetic vasopressors on $\mathrm{CVBF}$ in newborn rats during development of $\mathrm{ICH}$, we analyzed the sensitivity of sagittal vein to adrenaline in normal rats and stressed rats without ICH ( $4 \mathrm{~h}$ after stress) and with ICH ( $24 \mathrm{~h}$ after stress). In healthy rats, adrenaline induced the decrease in diameter of sagittal vein with tendency to increase in blood flow velocity that suggest about vasoconstriction of cerebral vein. Interestingly notice, after severe stress the pathological changes in CVBF in newborn rats were accompanied by the loss of sensitivity to adrenaline. Indeed, we observed that sagittal vein did not respond to adrenaline independently on the stages of development of ICH. These results suggest about the low functional capacity of sympathetic system in newborn rats that can be attributed to immaturity of adrenergic neurons and synapses in the brain in newborn rats. Adrenergic-related vasoconstriction effect is realized by activation of different types of alpha-adrenoreceptors. In experiments on newborn rat has been shown that density of alpha-adrenergic receptors in brain is very low during the first week after birth. Between day 7 and 14 there is a rapid increase in the density of alpha-adrenoreceptors. Adult levels are reached by the end of the second week. $^{56-58}$ Thus, the loss of sensitivity of cerebral veins to vasoconstrictor effect of sympathetic agonist - adrenaline under severe stress influences can be one of an important mechanism underlying pathological changes in CVBF and the decrease in resistance to development of $\mathrm{ICH}$.

Collectively, our results show that the decrease in CVBF related to the severity to the deleterious effect of stress on the brain hemodynamics. The masked period of ICH ( $4 \mathrm{~h}$ after stress) was characterized by early changes in CVBF due to the decrease in venous blood outflow. The incidence of ICH (24h after stress) was accompanied by progression of early pathological changes in CVBF and development of venous insufficiency. Our results are consistent with the findings of other researches who show that suppressed CVBF, hypotension and low cerebral perfusion pressure are associated with poor outcomes after ICH in children with brain injury $^{59-68}$ In adult patients with subarachnoid hemorrhage, investigators demonstrated that the fall $\mathrm{CBF}$ with oxygen desaturation is associated with a poor neurological outcome. ${ }^{69}$ Progressive decrease in $\mathrm{CBF}$ have been reported in patients with subarachnoid hemorrhage for three weeks after bleeding, and the decrease in blood flow is related to a worsening in clinical grade. ${ }^{70}$ The same results are obtained from animal data with experimental model of ICH. ${ }^{71}$

\section{Conclusion}

In summary, in experiments on newborn rats with stress-related ICH using DOCT we have shown that latent stage of $\mathrm{ICH}$ ( $4 \mathrm{~h}$ after stress) is characterized by decrease of venous blood outflow and the loss of sensitivity of sagittal vein to vasoconstrictor effect of adrenaline. The incidence of ICH $(24 \mathrm{~h}$ after stress) was accompanied by progression of early pathological changes in CVBF and development of venous insufficiency. Taking into consideration of this fact, we suggest that the suppression of CVBF related to the severity and to the deleterious effect of stress on the brain hemodynamics in newborn rats. These facts allow us to conclude that the venous insufficiency with the loss of vasoconstrictor response to adrenergic agonists are an informative and sensitive components of pattern of CVBF that 
can be important diagnostic criteria of risk of $\mathrm{ICH}$ development in newborns.

\section{Acknowledgments}

This work was supported in part by RF Governmental contracts 11.519.11.2035, 14.B37.21.0728, 14.B37.21.0563; 14.B37.21.0216 and grants: FiDiPro, TEKES Program (40111/11), Finland; SCOPES EC, Uzb/Switz/RF, Swiss NSF, IZ74ZO_137423/1; RF President's grant "Scientific Schools", 1177.2012.2., Russian Foundation for Basic Research Grant No. 1202-31204 mol-a and No. a-11-02-00560.

\section{References}

1. D. A. Osborn, N. Evans, M. Kluckow, "Hemodynamic and antecedent risk factors of early and late periventricular/intraventricular hemorrhage in premature infants," Pediatrics 112, 33-39 (2003).

2. E. H. Whitby, P. D. Griffiths, S. Rutter et al., "Frequency and natural of subdural haemorrhages in babies and relation to obstetric factors," Lancet 363, 846-851 (2004).

3. C. B. Looney, J. K. Smith, L. H. Merck et al., "Intracranial hemorrhage asymptomatic neonates: Prevalence on MR images and relationship obstetric and neonatal risk factors," Radiology 242, 535-541 (2007).

4. W. C. Hanigan, F. C. Powell, T. C. Miller, R. M. Wright, "Symptoatic intracranial hemorrhage in full-term infants," Childs Nerv. Syst. 11, 698-707 (1995).

5. A. S. Hojberg, F. Ebbesen, E. B. Lund, H. Agerholm, "Neurodevelopmental outcome in full-term infants with symptomatic intracranial haemorrhage of unknown aetiology," Dan. Med. Bull. 44, 439-442 (1997).

6. S. N. Gaupta, A. M. Kechli, U. S. Kanamalla, "Intracranial hemorrhage in term newborns: Management and outcomes," Pediatr. Neurol. 40, 1-12 (2009).

7. L. C. Jordan, J. T. Kleinman, A. E. Hillis, "Intracerebral hemorrhage volume predicts poor neurologic outcome in children," Stroke 40, 16661671 (2009).

8. J. K. Lynch, K. B. Nelson, "Epidemiology of perinatal stroke," Curr. Opin. Pediatr. 13, 499-505 (2003).

9. National Center for Health Statistics, Deaths, percentage of total deaths and death rates for the 10 leading causes of death in selected age groups, by race and sex: United States (2002-2005), Available at www.cdc.gov/nchs/data/nvsr/nvsr53/nvsr53_17. pdf (accessed on 16 June 2006).

10. L. L. Beslow, D. J. Licht, S. E. Smith, P. B. Storm, G. G. Heuer, R. A. Zimmerman, A. M. Feiler, S. E. Kasner, R. N. Ichord, L. C. Jordan, "Predictors of outcome in childhood intracerebral hemorrhage a prospective consecutive cohort study," Stroke 41, $313-318$ (2010).

11. W. D. Lo, "Childhood hemorrhagic stroke: An important but understudied problem," J. Child Neurol. 26(9), 1174-1185 (2011).

12. O. Semyachkina-Glushkovskaya, V. Lychagov, O. Bibikova, I. Semyachkin-Glushkovskiy, S. Sindeev, E. Zinchenko, M. Kassim, H. Braun, F. Al-Fatle, L. Al Hassani, V. Tuchin, "The assessment of pathological changes in cerebral blood flow in hypertensive rats with stress-induced intracranial hemorrhage using Doppler OCT: Particularities of arterial and venous alterations," J. Photon Lasers Med. 1-8 (2013).

13. M. A. Vilenskii, O. V. Semyachkina-Glushkovskaya, P. A. Timoshina, Ya. V. Kuznetsova, I. A. Semyachkin-Glushkovskii, D. N. Agafonov, V. V. Tuchin, "Laser speckle-imaging of blood microcirculation in the brain cortex of laboratory rats in stress," Quantum Electron. 42(6), 489-494 (2012).

14. J. Ahlqvist, "Stress-related intracerebral hemorrhage and the water-hammer effect," Stroke 32, 275-278 (2001).

15. G. Lammie, R. Lindley, S. Keir, M. Wiggam, "Stress-related primary intracerebral hemorrhage. Autopsy clues to underlying mechanism," Stroke 31, 1426-1428 (2000).

16. L. Caplan, "Intracerebral haemorrhage revisited," Neurology 38, 624-627 (1988).

17. H. Girouard, C. Iadecola, "Neurovascular coupling in the normal brain and in hypertension, stroke, and Alzheimer disease," J. Appl. Physiol. 100(1), 328-335 (2006).

18. D. Annibale, J. Hill, "Periventricular hemorrhageintraventricular hemorrhage," Emedicine.com, Available at http://emedicine.medscape.com/ article/976654-overview (accessed on 19 June 2007).

19. P. Ballabh, "Intraventricular hemorrhage in premature infants: Mechanism of disease," Pediatr Res. 67(1), 1-8 (2010).

20. P. Ballabh, A. Braun, M. Nedergaard, "Anatomic analysis of blood vessels in germinal matrix, cerebral cortex, and white matter in developing infants," Pediatr Res. 56(1), 117-124 (2004).

21. M. J. Purves, "The Physiology of the Cerebral Circulation," Syndics of the Cambridge University Press, p. 427 (1972).

22. J. A. Bevan, R. D. Bevan, S. P. Duckles, "Adrenergic regulation of vascular smooth muscle," 
in The Handbook of Physiology. Sec. 2 The Cardiovascular System. Vol. 2 Vascular Smooth Muscle, Chap. 18 pp. 515-566. Am. Physiol. Soc Bethesda (1981).

23. D. W. Busija, D. D. Heistad, "Factors involved in the physiological regulation of cerebral circulation," Rev. Physiol. Biochem. Pharmacol. 101, 161-211 (1984).

24. T. A. McCalden, "Sympathetic control of the cerebral circulation," J. Auton. Pharmacol. 1, 421-431 (1981).

25. P. A. Cassaglia, R. I. Griffiths, A. M. Walker, "Sympathetic nerve activity in the superior cervical ganglia increases in response to imposed increases in arterial pressure," Am. J. Physiol. - Regul. Integr. Comp. Physiol. AJP - Regul. Physiol. 294(4), 1255-1261 (2008).

26. J. L. Di Gennaro, D. C. Mack, A. Malakouti, J. J. Zimmerman, W. Armstead, M. S. Vavilala, "Use and effect of vasopressors after pediatric traumatic brain injury," Dev. Neurosci. 32(5-6), 420-430 (2011).

27. P. Sookplung, A. Siriussawakul, A. Malakouti, D. Sharma, J. Wang, M. Souter, R. Chesnut, M. Vavilala, "Vasopressor use and effect on blood pressure after severe adult traumatic brain injury," Neurocrit. Care 15(1), 46-54 (2011).

28. S. N. Kroppenstedt, U. W. Thomale, M. Griebenow, O. W. Sakowitz, K. D. Schaser, P. S. Mayr, A. W. Unterberg, J. F. Stover, "Effects of early and late intravenous norepinephrine infusion on cerebral perfusion, microcirculation, brain-tissue oxygenation, and edema formation in brain-injured rats," Crit. Care Med. 31(8), 2211-2221 (2003).

29. D. Pfister, S. P. Strebel, L. A. Steiner, "Effects of catecholamines on cerebral blood vessels in patients with traumatic brain injury," Eur. J. Anaesthesiol. 42, 98-103 (2008).

30. P. Sandor, "Nervous control of the cerebrovascular system: Doubts and facts," Neurochem. Int. 35, 237-259 (1999).

31. M. Green, G. Hutchins, "Positron emission tomography assessment of renal perfusion," Semin. Nephrol. 31(6), 291-299 (2011).

32. F. Bengel, T. Higuchi, M. Javadi, R. Lautamaki, "Cardiac positron emission tomography," J. Am. Coll. Cardiol. 54(1), 1-5 (2009).

33. J. Amerom, C. Kellenberger, S. Yoo, C. Macgowan, "Automated measurement and classification of pulmonary blood flow velocity patterns using phasecontrast MRI and correlation analysis," Magn. Reson. Imaging 27, 38-47 (2009).

34. T. Weber, H. von Tengg-Kobligk, A. KoppSchneider, J. Ley-Zaporozhan, H. Kauczor, S. Ley, "High-resolution phase-contrast MRI of aortic and pulmonary blood flow during rest and physical exercise using a MRI compatible bicycle ergometer," Eur. J. Radio. 80, 103-108 (2011).

35. J. Enmi, T. Hayashi, H. Watabe, H. Moriwaki, N. Yamada, H. Irida, "Measurement of cerebral blood flow with dynamic susceptibility contrast MRI and comparison with O-15 positron emission tomography," Int. Congr. Ser. 1265, 150-158 (2004).

36. A. Koretsky, "Early development of arterial spin labeling to measure regional brain blood flow by MRI," NeuroImage 62, 602-607 (2012).

37. P. Wintermark, A. Hansen, S. Warfield, D. Dukhovny, S. Soul, "Near-infrared spectroscopy vs magnetic resonance imaging to study brain perfusion in newborns with hypoxic-ischmic encephalopathy treated with hypothermia," NeuroImage (2013) in press, doi: 10.1016/j.neuroimage.2013.04.072.

38. M. Ferrari, V. Quaresima V, "A brief review on the history of human functional near-infrared spectroscopy (fNIRS) development and field of application," NeuroImage 63, 921-935 (2012).

39. J. Yao, K. Maslov, Y. Shi, L. Taber, L. Wang, "In vivo photoacoustic imaging of transverse blood flow by using Doppler broadening of bandwidth," Opt. Lett. 35(9), 1419-1421 (2010).

40. F. Helmchen, D. Kleinfeld, "In vivo measurements of blood flow and glial cell function with two-photon laser-scanning microscopy," Methods Enzymol. 444, 231-254 (2008).

41. M. Wintermark, M. Sesay, E. Barbier, K. Borbely, W. Dillon, J. Eastwood, C. Glenn, C. Grandin, S. Pedraza, J.-F. Soustiel, T. Nariai, G. Zaharchuk, J.-M. Caille, V. Dousset, H. Yonas, "Comparative overview of brain perfusion imaging techniques," Stroke 36, E83-E99 (2005).

42. E. Hillman, "Optical brain imaging in vivo: Techniques and application from animal to man," $J$. Biomed. Opt. 12(5), 051402 (2007).

43. K. Liem, G. Greisen, "Monitoring of cerebral haemodynamics in newborn infants," Early Hum. Dev. 86, 155-158 (2010).

44. V. Srinivasan, S. Sakadzic, I. Gorczynska, S. Ruvinskaya, W. Wu, J. Fujimoto, D. Boas, "Quantitative cerebral blood flow with optical coherence tomography," Opt. Exp. 18(3), 2477-2494 (2010).

45. M. Bhattacharjee, P. C. Ashok, K. Divakar Rao, S. K. Majumder, Y. Verma, P. K. Gupta, "Binary tissue classification studies on resected human breast tissue using optical coherence tomography images," J. Innov. Opt. Health Sci. 4(1), 59-66 (2011).

46. L. Xiqo, S. Guohua, W. Ling, D. Zhihua, Z. Yudong, "High-speed spectral domain optical coherence 
tomography signal processing with time-domain interpolation using graphics processing unit," $J$. Innov. Opt. Health Sci. 4(3), 325-335 (2011).

47. Y. Li-Ping, G. Jian-Chen, C. Li-Dek, M. Te-Lun, W. Jheng-Syong, L. Jiann-Der, C. Chien, "Polarizationsensitive optical coherence tomography using a modified balance detector," J. Innov. Opt. Health Sci. 5(4), 1250024 (2012).

48. S. Guennadi, D. Alexandre, "Real-time optical monitoring of capillarity grid spatial pattern in epithelium by spatially resolved diffuse reflectance probe," J. Innov. Opt. Health Sci. 5(2), 1250005 (2012).

49. O. Semyachkina-Glushkovskaya, O. Tichin, V. Lichagov et al., "The method of modeling of intracranial hemorrhage in newborn rats/Patent RF 072642," 24 October, 2012, p. 130.

50. J. J. Volpe, "Intracranial hemorrhage: Germinal matrix hemorrhage," Neurology of the Newborn J. J. Volpe, Ed., pp. 517-288, Saunders Elsevier, Philadelphia (2008).

51. H. S. Ghazi-Birry, W. R. Brown, D. M. Moody, V. R. Challa, S. M. Block, D. M. Reboussin, "Human germinal matrix: Venous origin of hemorrhage and vascular characteristics," Am. J. Neuroradiol. 18, 219-229 (1997).

52. B. G. Carter, W. Butt, A. Taylor, "ICP and CPP: Excellent predictors of long-term outcome in severely brain-injured children," Childs Nerv. Syst. 24, 245-251 (2008).

53. A. Català-Temprano, G. Claret Teruel, F. J. Cambra Lasaosa, O. M. Pons, J. A. Noguera, R. A. Palomeque, "Intracranial pressure and cerebral perfusion pressure as risk factors in children with traumatic brain injury," J. Neurosurg. 106(6), 463-466 (2007).

54. P. D. Adelson, S. L. Bratton, N. A. Carney, R. M. Chesnut, H. E. du Coudray, B. Goldstein, P. M. Kochanek, H. C. Miller, M. D. Partington, N. R. Selden, C. R. Warden, D. W. Wright, "Guidelines for the acute medical management of severe traumatic brain injury in infants, children, and adolescents," Pediatr. Crit. Care Med. 4(3), 12-18 (2003).

55. S. L. Bratton, R. M. Chestnut, J. Ghajar, F. F. McConnell Hammond, O. A. Harris, R. Hartl, G. T. Manley, A. Nemecek, D. W. Newell, G. Rosenthal, J. Schouten, L. Shutter, S. D. Timmons, J. S. Ullman, W. Videtta, J. E. Wilberger, D. W. Wright, "Guidelines for the management of severe traumatic brain injury," J. Neurotrauma 24(1), 7-13 (2007).

56. M. J. Morris, "Ontogeny of a1 and a2-adrenoceptors in rat brain," Brain Res. 190, 268-271 (1980).
57. H. K. Happe, "Alpha-2 adrenergic receptor functional coupling to $\mathrm{G}$ proteins in rat brain during postnatal development," J. Pharmacol. Exp. Ther. 288, 1134-1142 (1999).

58. J. V. Bartolome, R. J. Kavlock, T. Cowdery, L. Orband-Miller, T. A. Slotkin, "Development of adrenergic receptor binding sites in brain regions of the neonatal rat: Effects of prenatal or postnatal exposure to methylmercury," Neurotoxicol. 8, 1-14 (1987).

59. P. J. Andrews, D. H. Sleeman, P. F. Statham, A. McQuatt, V. Corruble, P. A. Jones, T. P. Howells, C. S. Macmillan, "Predicting recovery in patients suffering from traumatic brain injury by using admission variables and physiologic data: A comparison between decision tree analysis and logistic regression," J. Neurosurg. 97, 326-336 (2002).

60. B. G. Carter, W. Butt, A. Taylor, "ICP and CPP: Excellent predictors of long-term outcome in severely brain-injured children," Childs Nerv. Syst. 24, 245-251 (2008).

61. A. Català-Temprano, C. G. Teruel, C. F. J. Lasaosa, O. M. Pons, J. A. Noguera, R. A. Palomeque, "Intracranial pressure and cerebral perfusion pressure as risk factors in children with traumatic brain injury," J. Neurosurg. 106(6), 463-466 (2007).

62. I. R. Chamber, P. A. Jones, T. Y. M. Lo, R. J. Forsyth, B. Fulton, P. J. D. Andrews, A. D. Mendelow, R. A. Minns, "Critical thresholds of intracranial pressure and cerebral perfusion pressure related to age in pediatric head injury," J. Neurol. Neurosurg. Psychiatry. 77, 234-240 (2006).

63. D. G. Changaris, C. P. McGraw, J. D. Richardson, H. D. Garretson, E. J. Arpin, C. B. Shields, "Correlation of cerebral perfusion pressure and Glasgow Coma Scale to outcome," J. Trauma. 27, 1007-1013 (1987).

64. G. L. Clifton, E. R. Miller, S. C. Choi, H. S. Levin, "Fluid thresholds and outcome from severe brain injury," Crit. Care Med. 30, 739-745 (2002).

65. C. Downard, F. Hulka, R. J. Mullins, J. Piatt, R. Chesnut, P. Quint, N. C. Mann, "Relationship of cerebral perfusion pressure and survival in pediatric braininjured patients," J. Trauma. 49, 654-658 (2000).

66. A. C. Elias-Jones, J. A. Punt, A. E. Turnbull, T. Jaspan, "Management and outcome of severe head injuries in the Trent region 1985-1990," Arch. Dis. Child. 67, 1430-1435 (1992).

67. R. M. Hackbarth, K. M. Rzeszutko, G. Sturm, J. Donders, A. S. Kuldanek, D. J. Sanfilippo, "Survival and functional outcome in traumatic brain injury: A retrospective review and analysis of predictive factors," Crit. Care Med. 30, 1630-1635 (2002). 
68. G. Kaiser, J. Pfenninger, "Effect of neurointensive care upon outcome following severe head injuries in childhood: A preliminary report," Neuropediatrics 15, 68-75 (1984).

69. K. Keining, G. Schneider, T. Bardt, A. Unterberg, W. Lanksch, "Bifrontal measurements of brain tissue PO2 in comatose patients," Acta Neurochir. Suppl. 71, 172-183 (1998).
70. C. Meyer, D. Lowe, M. Meyer, P. Richardson, G. Neil-Dwyer, "Progressive change in cerebral blood flow during the first three weeks after subarachnoid hemorrhage," Neurosurgery 12, 58-76 (1983).

71. Y. Jiang, J. Wu, R. Keep, Y. Hua, J. Hoff, G. Xi, "Hypoxia-inducible factor-1alpha accumulation in the brain after experimental intracerebral hemorrhage," J. Cereb. Blood Flow Metab. 22(6), 689-696 (2002). 